\title{
Caractérisation de l'activité protéolytique de différentes populations bactériennes du rumen
}

\author{
D Debroas, G Blanchart \\ ENSAIA, laboratoire de Zootechnie INRA, 2, avenue de la Forêt-de-Haye, 54500 Vandoeuvre, France
}

Summary - Proteolytic activity characterization of different rumen bacterial populations. In vitro trials were conducted to determine the efficiency of proteolysis and the kinds of enzymes produced by 3 groups of rumen bacteria. All antibiotics or heat-resistant bacterial inocula display rather high proteolytic activities. Metronidazole-resistant bacteria had proteolytic activities of the same type as the mixed population in vivo.

Les bactéries protéolytiques isolées du rumen sont diverses. Elles appartiennent aux genres : Bacteroides, Butyrivibrio, Streptococcus, Clostridium, Eubacterium et Selenomonas (Wallace et Brammall, 1985). La connaissance des espèces bactériennes protéolytiques, de leurs activités protéolytiques, et la caractérisation de leurs protéases sont la première étape dans la recherche des moyens de réduire les pertes en composés protéiques de haute qualité qui pourraient être valorisés dans l'intestin du ruminant. L'objectif de cette étude est ainsi de caractériser les activités protéolytiques et les types de protéases produites par différentes populations bactériennes du rumen.

Matériel et méthodes - Différentes popula-
tions bactériennes du rumen sont sélectionnées
par l'action de la monensine (inhibiteur des
Gram +) ou du métronidazole (inhibiteur des
Gram - anaérobies) introduits à des concentra-
tions de $5 \mathrm{ppm}$ ou par chauffage à $80^{\circ} \mathrm{C}$ pen-
dant 10 min. L'activité protéolytique des popula-
tions ainsi obtenues et du témoin non traité est
mesurée par la disparition de caséine et l'appari-
tion de peptides, selon la méthode proposée par
Russell et al (1983). L'activité protéolytique des
mêmes populations est ensuite caractérisée par
leur aptitude à maintenir une hydrolyse de l'azo-
caséine lorsqu'on ajoute au milieu des inhibi-
teurs de certains types d'activité protéasique
(acide éthylènediaminetétra-acétique, iodoacé-
tate, phénylméthylsulfonylfluoride et L-cystéine).
Cette caractérisation est pratiquée par l'incuba- tion à $39^{\circ} \mathrm{C}$ d'azocaséine par un extrait de culture en phase exponentielle de croissance, en présence ou non d'inhibiteur (Brock et al, 1982).

Résultats et discussion - Toutes les populations bactériennes résistant aux traitements sont capables de dégrader la caséine dans de fortes proportions (fig 1). Dans le témoin et en présence de monensine ou de métronidazole, la dégradation de la caséine dépasse $80 \%$. Les bactéries sporulées ont une action légèrement plus faible $(65 \%)$. Une accumulation de peptides se produit lors de toutes les fermentations, excepté après un chauffage (fig 1D). Cependant, en présence de monensine, l'apparition des peptides est plus rapide (fig 1B). Lorsque la source azotée est de la caséine, l'étape limitante de l'utilisation de la protéine est l'absorption des peptides par les bactéries, et non l'hydrolyse de la protéine elle-même. Les protéases synthétisées en présence de monensine sont faiblement inhibées et peuvent donc être difficilement caractérisées (tableau I). Les enzymes protéolytiques produites après un traitement thermique sont des métalloprotéases et des sérine protéases. L'action fortement inhibitrice du PMSF, de I'EDTA et de l'iodoacétate sur les enzymes produites en présence de métronidazole indique la présence de sérine protéases, de métalloprotéases et de cystéine protéases respectivement. Ce profil d'inhibi- 
tion est identique à ceux obtenus sur du jus de rumen d'animaux recevant une alimentation à base de foin et de concentré (Brock et al, 1982) et proche de ceux obtenus sur Streptococcus bovis et Butyrivibrio fibrisolvens en cultures pures (Wallace et Brammall, 1985) qui ne sont sensibles qu'aux antibiotiques spécifiques des Gram+ (Nagaraja et Taylor, 1987). Par la qualité de leurs protéases, ce sont les bactéries protéolytiques se développant en présence de métronidazole, Streptococcus bovis et Butyrivibrio fibrisolvens, qui se rapprochent le plus du profil couramment observé dans le rumen. Ces résultats confirment l'importante activité protéolytique de ces 2 es- pèces (Hazlewood et al, 1983). lls montrent aussi que les bactéries sporulées anaérobies (Clostridiae), qui ont rarement été étudiées, peuvent participer à la protéolyse.

Brock FM, Forsberg CW, Buchanan-Smith JG (1982) App/ Environ Microbiol 44, 561-569

Hazlewood GP, Orpin CG, Greenwood Y, Black ME (1983) Appl Environ Microbiol 45, 17801784

Nagaraja TG, Taylor MB (1987) App/ Environ Microbiol 53, 1620-1625

Russell JB, Sniffen CJ, Van Soest PJ (1983) $J$ Dairy Sci 66, 763-775

Wallace RJ, Brammall ML (1985) J Gen Microbiol 131, 821-832
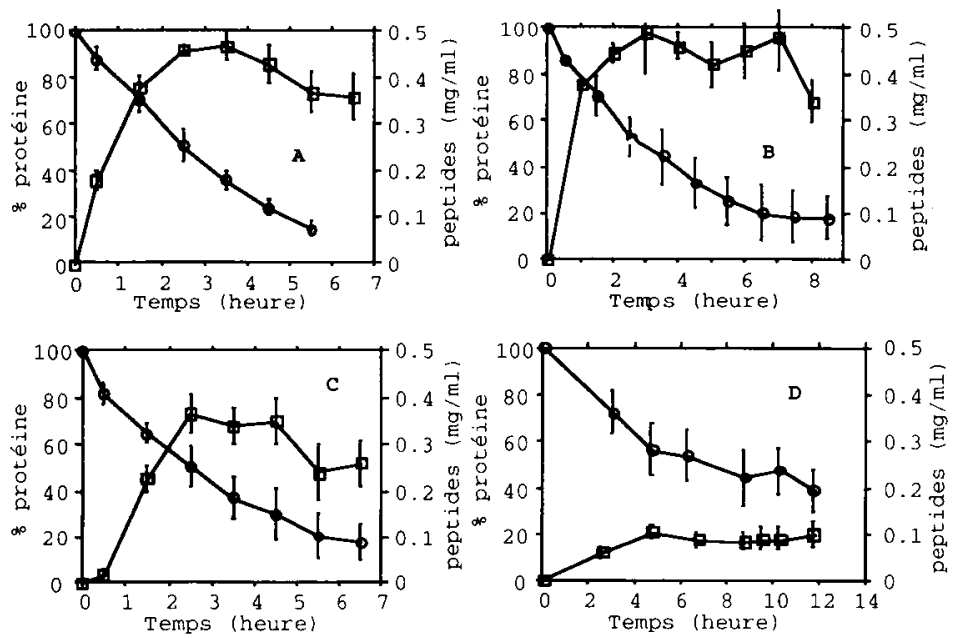

Fig 1. Évolution de la teneur en protéines $(-\odot)$ et en peptides $(\square)$ pendant la croissance bactérienne. A. Témoin; B. Monensine; C. Métronidazole; D. Choc thermique. $(n=3)$

Tableau I. Effet des inhibiteurs sur les protéases produites après différents traitements $(n=3)$.

\begin{tabular}{llll}
\hline Inhibiteurs & Monensine & Métronidazole & Choc thermique \\
\hline EDTA & $80,6 \pm 9$ & $56,9 \pm 4$ & \\
lodoacétate & $90,9 \pm 7,9$ & $47,4 \pm 3$ & $86,4 \pm 9$ \\
PMSF & $82,6 \pm 12,2$ & $50,7 \pm 8$ & $92,9 \pm 6,8$ \\
L-cystéine & $71,1 \pm 8,9$ & $79,1 \pm 7$ & $21,2 \pm 6,7$ \\
& & & $39,9 \pm 9,8$ \\
\hline
\end{tabular}

